\title{
Copulatory behavior of Mongolian gerbils (Meriones unguiculatus)*
}

\author{
HARRY N. DAVIS, JR., DANIEL Q. ESTEP, and DONALD A. DEWSBURY \\ University of Florida, Gainesıille. Florida 32611
}

\begin{abstract}
Three experiments were conducted to provide a quantitative description of copulation in Mongolian gerbils (Meriones unguiculatus). The overall copulatory pattern of gerbils may be characterized as containing multiple intromissions, multiple ejaculations, no intravaginal thrusting, and no lock. Mean intromission frequencies failed to approach the exceptionally high values reported by previous workers. As the present data indicate that gerbils lie within rather than outside the range of performance of other muroid rodents, it is suggested that earlier hypotheses regarding unusual insensitivity of gerbil reproductive systems are unnecessary. Sexual satiety $(30 \mathrm{~min}$ with no intromissions) was attained following a mean of 4.8-6.9 ejaculations. In contrast to most other species, males typically failed to complete the final ejaculatory series. even after many intromissions. Implications of this unusual mode of development of satiety are discussed.
\end{abstract}

An essential prerequisite to comprehensive understanding of the controlling mechanisms and adaptive significance of mammalian copulatory behavior is a catalogue of descriptive normative data on a variety of species (Parkes, Mathews, \& Rowlands, 1966; Clemens, 1966: Dewsbury, 1972a). Such descriptions must be complete, quantitative, and representative of the target population under the stated testing conditions. Accurate quantitative data on the complete pattern are especially important, since apparently smail variations in copulatory behavior can be of considerable significance for successful reproduction (Adler, 1969; Adler \& Zoloth, 1970).

Given the increasing use of Mongolian gerbils as research animals (Thiessen, 1968: Gulotta, 1971). information regarding their reproductive behavior is of particular importance. The first quantitative study of copulation in this species was provided by Kuehn and Zucker (1968). The copulatory pattern they described contained no lock, no intravaginal thrusting, multiple intromissions prerequisite to ejaculation, and multiple ejaculations (see Dewsbury. 1972a). The most interesting feature of the pattern was the number of intromissions preceding ejaculation (intromission frequency). Means of 51, 25, and 23, respectively, were reported for the first three ejaculatory series. These values are so much higher than those of other species of muroid rodents as to border on a qualitative difference, a difference with important implications for the reproductive physiology of gerbils. If replicable, these

*Supported by Grants GB-28554 and GB-33837X from the National Science Foundation. Portions of this work were submitted by H. N. D. in partial fulfillment of the requirements for the degree of Master of Science at the University of Florida. Hormones were provided through the courtesy of the Schering Corporation, Bloomfield. New Jersey. Please send requests for reprints to D. A. Dewsbury, Department of Psychology. University of Florida, Gainesville. Florida 32611. atypically high intromission frequencies "may reflect a basic insensitivity of the male's ejaculatory mechanism. or a functional aspect of reproduction [Kuehn \& Zucker, 1968.p. 751]."

The present research was designed both to extend and to reexamine certain aspects of the Kuehn and Zucker (1968) study. More specifically, the latter authors provided no data on sexual satiety in gerbils. As satiety represents a critical feature of the total copulatory pattern (Dewsbury, 1971, 1972a), quantitative data are provided in the present report. Beyond this. there are grounds for suspicion regarding the generality of the data presented by Kuehn and Zucker (1968) for intromission frequency. Thus, pilot work with gerbils in this laboratory indicates that individual differences in this measure may be extremely large. Of the three animals observed here, one had a first series mean of 142, whereas the other two had means of only 17 and 20. Unfortunately, since Kuehn and Zucker reported no measures of intersubject variability, it is impossible to determine the range of values they observed. However. the fact that a greater than $50 \%$ reduction in intromission frequency from the first to later series in their study was not statistically significant suggests that individual differences in performance must have been substantial. Considering, further. that their data are based upon just six male-female pairs given an unspecified number of tests, additional normative data would clearly seem warranted.

\section{METHOD}

Data are reported for 13 male and 23 fenule gerbils. These animals were purchased from Tumblebrook Farm. Brant Laki. New York, at approximately 90 days of age. Ot an additional 10 males. seven died or tailed to copulate reliably after completin: one to tive positive tests. The remaining three males fidiled io copulate in their initial seven tests.

All mating tests were conducted in sircular Plexiglas arenas 
Table 1

Means, Standard Errors, and Results of Statistical Analysis of Standard Measures of Copulatory Behavior for the Initial Three Series

\begin{tabular}{|c|c|c|c|c|c|c|c|c|}
\hline \multirow[b]{2}{*}{ Measure* } & \multirow[b]{2}{*}{ Seties } & & & \multirow[b]{2}{*}{ SE } & \multirow[b]{2}{*}{$F$} & \multicolumn{3}{|c|}{$p^{\div}$} \\
\hline & & & & & & 1 by 2 & 1 by 3 & 2 by 3 \\
\hline EL & $\begin{array}{l}1 \\
2 \\
3\end{array}$ & $\begin{array}{l}442 \\
115 \\
110\end{array}$ & $\begin{array}{r}(1117) \\
(479) \\
(411)\end{array}$ & $\begin{array}{r}32.1 \\
4.5 \\
5.7\end{array}$ & 126.83 & $<.01$ & $<.01$ & n.s. \\
\hline IF & $\begin{array}{l}1 \\
2 \\
3\end{array}$ & $\begin{array}{r}14.2 \\
5.6 \\
5.8\end{array}$ & $\begin{array}{l}(51) \\
(25) \\
(23)\end{array}$ & $\begin{array}{l}0.7 \\
0.2 \\
0.2\end{array}$ & 199.10 & $<.01$ & $<.01$ & n.s. \\
\hline MIIII & $\begin{array}{l}1 \\
2 \\
3\end{array}$ & $\begin{array}{l}31.3 \\
21.0 \\
19.2\end{array}$ & $\begin{array}{l}(23.4) \\
(19.6) \\
(19.3)\end{array}$ & $\begin{array}{l}2.0 \\
1.3 \\
1.0\end{array}$ & 39.41 & $<.01$ & $<.01$ & n.s. \\
\hline $\mathrm{MF}$ & $\begin{array}{l}1 \\
2 \\
3\end{array}$ & $\begin{array}{l}8.7 \\
1.5 \\
1.3\end{array}$ & $\begin{array}{l}- \\
-\end{array}$ & $\begin{array}{l}1.2 \\
0.2 \\
0.3\end{array}$ & 37.68 & $<.01$ & $<.01$ & n.s. \\
\hline PEI & $\begin{array}{l}1 \\
2\end{array}$ & $\begin{array}{l}189 \\
191\end{array}$ & $\begin{array}{l}(218) \\
(249)\end{array}$ & $\begin{array}{l}4.6 \\
8.0\end{array}$ & $<1$ (n.s.) & - & - & - \\
\hline
\end{tabular}

*All temporal measures are given in seconds.

**Mean performance data from Kuehn and Zucker 11968 ) are presented in parentheses next to comparable measures of the present study:

tp values from Newman-Kuels (Winer, 1962).

$38 \mathrm{~cm}$ in diam and $58 \mathrm{~cm}$ high. Arenas were placed on a table covered with a commercislly produced litter material. Copulatory events were recorded manually on an Esterline-Angus operations recorder.

Animals were maintained on a reversed $14: 10$ light-dark crcle. with light onset at 6 p.m. Males were housed individually in Plexiglas cages $19 \times 29 \times 13 \mathrm{~cm}$. Females were ovariectomized upon arrival in the laboratory and housed in Plexiglas cages $48 \times 27 \times 13 \mathrm{~cm}$. Purina lab chow was supplemented weekly with fresh cabbage. Animals were permitted 3 weeks to adapt to the laboratory regime before testing, and each male was given 45-90 min to adapt to the arenas during this time.

Females were brought into behavioral estrus with intramuscular injections of $0.06 \mathrm{mg}$ estradiol benzoate $48 \mathrm{~h}$ before testing and $0.4 \mathrm{mg}$ progesterone $9 \mathrm{~h}$ before testing.

Tests were conducted in dim red light during the early part of the dark phase of the light-dark cycle. Tests were initiated with the introduction of the female into the arena $5 \mathrm{~min}$ after introduction of the male.

Following a single positive pretest, five tests of copulatory behavior were conducted at $2 \cdot$ week intervals. These tests were continued until the third ejaculation if copulation occurred or for $30 \mathrm{~min}$ if it did not. Each male also received a final test that continued until a satiety criterion of $30 \mathrm{~min}$ with no intromissions was reached. No male was tested with the same female more than once in any of these tests.

The standard measures of copulatory behavior in rats (Beach \& Jordan, 1956: Larsson, 1956) were adapted for use with gerbils. In this system. the term "series" refers to a group of mounts and intromissions leading up to and including an ejaculation. The following measures were determined: mount latency $(M L)$-latency from introduction of the female to the first mount with thrusting; intromission latency (IL)-latency from introduction of the female to the first mount with vaginal penetration: ejaculation latency (EL)-latency from the first intromission of a series to ejaculation; intromission frequency (IF) - the number of intromissions in a series; mount frequency $(M F)$-the number of mounts with thrusting but without intromission in a series; mean interintromission interval (MIII)-mean interval separating intromissions within a series; postejaculatory interval (PEI)-latency from ejaculation to the resumption of copulation as indicated by the next intromission; ejaculation frequency $(E F)$-number of ejaculations preceding at tainment of the satiety criterion. These abbreviations are used with a hyphen and number to indicate series (e.g., EL-2).

\section{RESULTS}

Copulation ensued rather rapidly following introduction of the female. Mean mount and intromission latencies were 316 and $479 \mathrm{sec}$, respectively. Values reported by Kuehn and Zucker (1968) were somewhat lower $(\mathrm{ML}=218 \mathrm{sec}$, IL $=237 \mathrm{sec}$ ).

The remaining measures are characteristic of each individual series. Changes in these measures across the first three series were analyzed with analyses of variance. Where significant main effects obtained, individual comparisons among means were computed using the Newman-Keuls procedure (Winer, 1962). Results of these analyses are presented together with means and standard errors in Table 1 . Because individual differences are particularly important in interpreting these data, means on selected measures are presented for each male in Table 2.

The mean number of intromissions required to reach ejaculation in each of the first three series was approximately one-fourth of that reported by Kuehn and Zucker (1968). There was a highly reliable decrease in IF from the first series to the second and third, whereas IFs in the latter two series did not differ significantly. IF-1 was greater than IF-2 in $95 \%$ of the tests, while IF-2 was greater than IF-3 in just $38 \%$ of the tests. Variability across animals was relatively low (range for $I F-1=11.5-19.3$ ), and the reduction in later series was evident for all males (Table 2).

The pattern of change across series for EL; MIII, and MF paralleled that noted above for IF (Table 1). For each measure, the value in the first series was significantly higher than that in the next two series. Mean EL, MF, and MIII decreased from the first to the second series in $100 \%, 87 \%$, and $79 \%$ of the tests, respectively. Values for MIII approximated those of 
Table 2

Mean Scores of Individual Gerbils on Selected Measures of Copulatory Behavior

\begin{tabular}{|c|c|c|c|c|c|c|c|c|c|}
\hline$S$ & $\mathrm{IL}$ & EL-1 & EL-2 & EL-3 & IF-I & IF -2 & IF-3 & PEI-1 & PEI-2 \\
\hline 1 & 111 & 349 & 111 & 122 & 17.3 & 6.5 & 7.3 & 170 & 154 \\
\hline 2 & 424 & 602 & 147 & 153 & 14.5 & 4.8 & 6.3 & 200 & 185 \\
\hline 3 & 347 & 679 & 126 & 124 & 16.3 & 5.3 & 5.2 & 218 & 262 \\
\hline 4 & 466 & 500 & 118 & 121 & 12.0 & 4.7 & 6.0 & 181 & 179 \\
\hline 5 & 695 & 522 & 112 & 109 & 19.3 & 7.0 & 6.5 & 178 & 170 \\
\hline 6 & 386 & 376 & 122 & 114 & 12.2 & 5.8 & 5.0 & 196 & 187 \\
\hline 7 & 524 & 294 & 98 & 85 & 12.8 & 6.2 & 5.8 & 163 & 164 \\
\hline 8 & 762 & 397 & 104 & 107 & 15.3 & 6.5 & 7.0 & 206 & 208 \\
\hline 9 & 451 & 345 & 108 & 87 & 11.5 & 5.7 & 5.0 & 169 & 188 \\
\hline 10 & 516 & 367 & 99 & 78 & 11.8 & 4.3 & 4.7 & 196 & 186 \\
\hline 11 & 439 & 347 & 123 & 108 & 13.3 & 5.2 & 4.7 & 206 & 232 \\
\hline 12 & 671 & 532 & 134 & 126 & 15.5 & 5.5 & 5.8 & 181 & 182 \\
\hline 13 & 438 & 438 & 87 & 95 & 12.7 & 4.7 & 5.7 & 196 & 180 \\
\hline
\end{tabular}

Kuehn and Zucker (1968). Values observed here for EL were much lower, reflecting in part the already mentioned lower IFs found in the present work. Kuehn and Zucker reported no data for MF.

The difference between PEIs of the first two series was not statistically significant. Absolute values for this measure were slightly below those of Kuehn and Zucker.

The analyses of variance revealed significant differences across tests for $\mathrm{EL}(\mathrm{F}=3.28$, $\mathrm{df}=5 / 60$, $\mathrm{p}<.05)$ and PEI $(\mathrm{F}=3.44, \mathrm{df}=5 / 60, \mathrm{p}<.01)$. In neither case was the Test by Series interaction significant. Trend analysis using orthogonal polynomials (Winer, 1962) indicated a significant linear decrease in EL and PEI across tests ( $p<.05)$.

The sixth test was continued to a satiety criterion of $30 \mathrm{~min}$ with no intromissions. Mean ejaculation frequency was 6.9 , with a range of 5-9 ejaculations.

Means and standard errors were calculated for the standard measure in each of the last three complete series of the sixth test. Grouping the data in this manner (i.e., starting with the last complete series and working back toward the first) provides an effective way to analyze changes in behavior as satiety is approached (Dewsbury, 1968). These data were analyzed as were the data from the first three series. Results are presented in Table 3, where $\mathrm{N}$ refers to the last complete series before satiety, N-1 to the next to the last, and so on. It can be seen that EL, IF, MIII, and PEI all increased significantly in the last complete series.

For five males, the satiety criterion was reached between series as a failure to resume copulation within $30 \mathrm{~min}$ following the last ejaculation. The other males reinitiated a series but failed to complete it with ejaculation. These "incomplete series" had a mean duration of $3202 \mathrm{sec}(\mathrm{SE}=872 \mathrm{sec})$, not including the $30-\mathrm{min}$ satiety criterion. They contained a mean of 58.3 $(\mathrm{SE}=20.6)$ intromissions.

Seven males failed to complete testing, and their data were not included in the above analyses. These animals did finish a total of 21 positive tests, however, and the

Table 3

Means, Standard Errors, and Results of Statistical Analysis of Standard Measures of Copulatory Behavior for the Last Three Series Before Satiety

\begin{tabular}{|c|c|c|c|c|c|c|c|}
\hline \multirow[b]{2}{*}{ Measure } & \multirow[b]{2}{*}{ Series } & \multirow[b]{2}{*}{ Mean } & \multirow[b]{2}{*}{ SE } & \multirow[b]{2}{*}{$\mathrm{F}$} & \multicolumn{3}{|c|}{$p$} \\
\hline & & & & & $\mathrm{N}-2$ by $\mathrm{N}-1$ & $\mathrm{~N}-2$ by $\mathrm{N}$ & $\mathrm{N}-1$ by $\mathrm{N}$ \\
\hline $\mathrm{EL}$ & $\begin{array}{l}\mathrm{N}-2 \\
\mathrm{~N}-1 \\
\mathrm{~N}\end{array}$ & $\begin{array}{l}144 \\
232 \\
520\end{array}$ & $\begin{array}{r}24.3 \\
42.8 \\
133.6\end{array}$ & 7.72 & n.s. & $<.01$ & $<.05$ \\
\hline IF & $\begin{array}{l}\mathrm{N}-2 \\
\mathrm{~N}-1^{-} \\
\mathrm{N}\end{array}$ & $\begin{array}{r}7.9 \\
11.0 \\
15.7\end{array}$ & $\begin{array}{l}2.0 \\
3.1 \\
3.4\end{array}$ & 8.57 & n.s. & $<.01$ & $<.05$ \\
\hline MIll & $\begin{array}{l}\mathrm{N}-2 \\
\mathrm{~N}-1 \\
\mathrm{~N}\end{array}$ & $\begin{array}{l}20.1 \\
23.4 \\
32.6\end{array}$ & $\begin{array}{l}1.7 \\
1.7 \\
3.5\end{array}$ & 9.88 & n.s. & $<.01$ & $<.05$ \\
\hline MF & $\begin{array}{l}\mathrm{N}-2 \\
\mathrm{~N}-1 \\
\mathrm{~N}\end{array}$ & $\begin{array}{l}2.2 \\
3.7 \\
2.7\end{array}$ & $\begin{array}{l}1.3 \\
1.4 \\
1.3\end{array}$ & 4.89 n.s. & - & - & - \\
\hline PEI & $\begin{array}{l}\mathrm{N}-2 \\
\mathrm{~N}-1 \\
\mathrm{~N} \\
\end{array}$ & $\begin{array}{l}231 \\
262 \\
497 \\
\end{array}$ & $\begin{array}{l}17.8 \\
14.7 \\
82.3 \\
\end{array}$ & 5.99 & n.s. & $<.01$ & $<.01$ \\
\hline
\end{tabular}




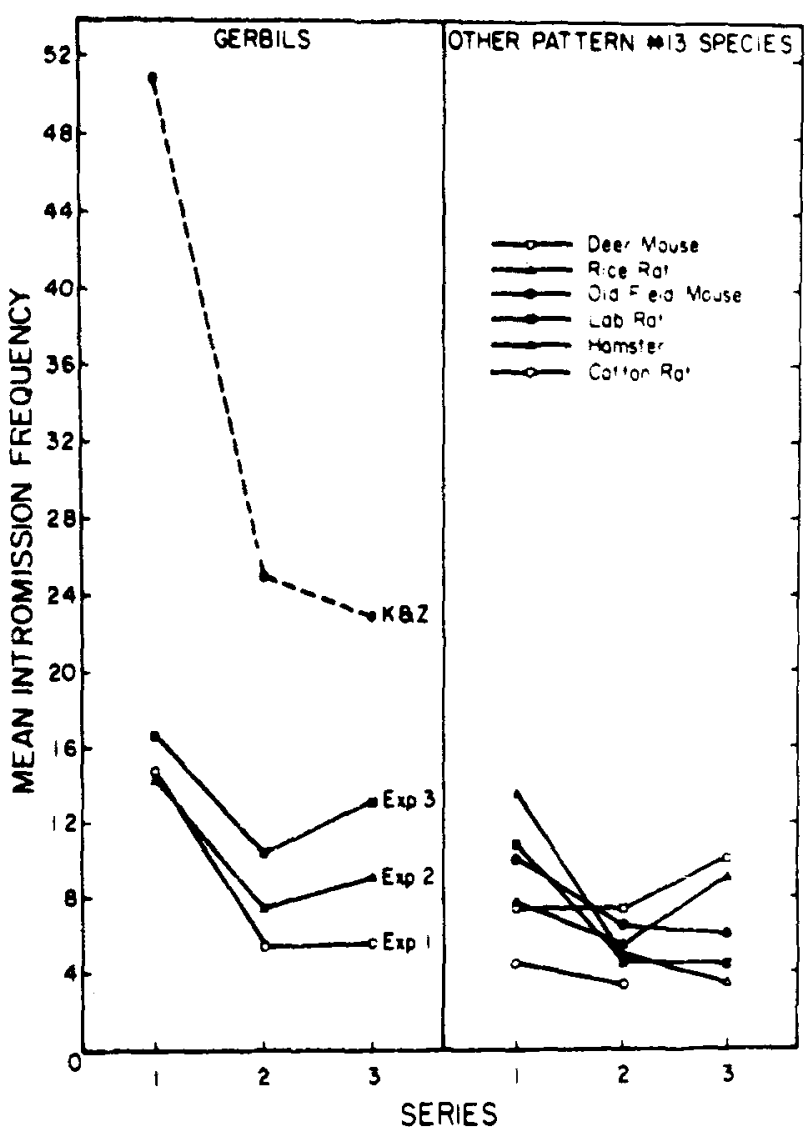

Fig. 1. Mean intromission frequencies for Mongolian gerbils in Experiments I, II, and III as compared both to earlier work with this species (Kuehn \& Zucker, 1968) and to other species of muroid rodents with similar patterns, including laboratory rats (Dewsbury, 1968), deermice (Clemens, 1969), old-field mice (Dewsbury, 1971), rice rats (Dewsbury, 1970), cotton rats (Dewsbury, 1972b), and hamsters (Bunnell, Boland, \& Dewsbury, in preparation).

data from these tests closely matched those from the main body. For example, mean IFs in the first three series were, respectively, 14.2,6.5, and 7.2 (cf. Table 1).

\section{DISCUSSION}

The present study was designed both to replicate and to extend the descriptive analysis of copulation. in Mongolian gerbils presented by Kuehn and Zucker (1968). Results resemble those of the latter authors in many regards. First of all, the basic copulatory pattern of gerbils is confirmed to be one of multiple intromissions, multiple ejaculations, no lock, and no intravaginal thrusting (Pattern 13 of Dewsbury, 1972a). Second, absolute values for the standard quantitative measures used here and by Kuehn and Zucker are, with the exception of EL and IF, quite close. Finally, patterns of change in the standard measures across successive series also are generally parallel.

The primary difference between the present work and that of Kuehn and Zucker concerns the data on intromission frequency. Thus, values observed here for this measure fail even to approach the exceptionally high values reported by the latter authors. Ejaculation latencies were also substantially lower in the present work. However, since the spacing of intromissions (MIII) in the two reports was approximately the same. differences in $E L$ are perhaps best viewed as secondary effects of the differences in IF.

Kuehn and Zucker housed and tested their animals as stable male-female pairs, whereas males in the present study (Experiment I) were housed individually, and no male was tested with the same female more than once. When our results failed to confirm the unusually high IFs reported by Kuehn and Zucker (1968), it seemed reasonable that this procedural difference might have been responsible. Indeed, with this one exception, an attempt had been made to duplicate the methodological details of their study as closely as possible, even to the wattage and location of the red light bulb used during testing. Therefore, two additional studies (Experiments II and III) were conducted to investigate the effects of pairing. Experiment II consisted of pairing the males and females from Experiment 1 for a total of 6 weeks, with satiety tests conducted at the end of the third and sixth weeks of pairing. Experiment III was conducted as a direct replication of the Kuehn and Zucker (1968) study using a new group of 10 male-female pairs. Each pair received three tests continued to the third ejaculation, and eight of these pairs subsequently received two tests continued to satiety. In general, results of these two studies closely approximated those of Experiment I, both with respect to absolute values recorded for the standard measures and with respect to changes in these measures across series. Although IFs were generally higher in Experiments II and II as compared to Experiment $I$, they still failed even to approach the values of Kuehn and Zucker, particularly in the first series (Fig. 1). Mean EFs in Experiment II and III were 6.7 (range $=3.11$ ) and 4.8 (range $=3.8$ ), respectively, with 36 out of the total of 42 satiety tests ending within an "incomplete series."

Assuming that pairing does not account for the conflicting data on IF, a likely explanation lies in sampling. As stated above, one animal with a first series mean IF of 142 was observed here during pilot work with gerbils. Although never formally tested, another male with comparably high scores has also been observed in this laboratory. While present results indicate that animals such as these are uncommon, it seems likely that Kuehn and Zucker may have observed one or more of them in their study. In a sample of only six males, merely one such animal could produce group means resembling those of the latter authors, even if all of the other animals displayed IFs similar to those recorded here. Moreover, the variability introduced by such an animal would explain the surprising failure to find any significant differences in IF across series in their study. Without any discussion of variability by Kuehn and Zucker, it is impossible to determine conclusively whether they did in fact observe one or more atypical animals like those described above. Given available 
information. however. a sampling difference of this kind seems a likely interpretation.

Finally. gerbils have been bred and used for research purposes in the (inited States for a comparativety short time (see Thiessen. 1968) and may be undergoing rapid genetic change either through inbreeding or through "selection" for laboratory use. Accordingly, it is possible that the divergence of our results from those reported by Kuehn and Zucker may reflect such changes rather than a sampling difference, as suggested above. While this may be one factor, it still leaves unexplained the fact that rather dramatic changes in mean IF across series in the Kuehn and Zucker study failed to attain statistical significance.

We conclude that. while occasional animals with exceptionally high IFs do exist. the typical pattern of gerbils contains far fewer intromissions. The implications of this conclusion are portrayed in Fig. 1. Rather than lying outside the range of IFs reported for other species of muroid rodents with this same basic pattern (i.e., Pattern 13), gerbils appear to be a part of it. Speculation regarding unusual insensitivity of the male or female reproductive systems appears inappropriate.

The major new aspect of the present research involved the collection of data on sexual satiety. The standard criterion of $30 \mathrm{~min}$ with no intromissions was reached following a mean of 4.8-6.9 ejaculations. These EFs fall well within the range of scores reported for other Pattern 13 species (see Dewsbury. 1972b). For example, gerbils achieved fewer ejaculations than the 9.0 of hamsters (Beach \& Rabedeau. 1959) but more than the 2.1 of cotton rats (Dewsbury, 1972b).

As in several other species (e.g., Dewsbury. 1968. 1971), the copulatory behavior of gerbils changed markedly as satiety was approached. With the exception of MF, each of the standard measures increased progressively over the last three complete series. Thus. progressively more time and stimulation were required to produce ejaculation. and more time was required to recover from it. These changes wese accompanied by a general breakdown in the tightly organized temporal patterning of copulations characteristic of earlier series and by a dramatic increase in variability both within and across Ss.

Gerbils typically attained the satiety criterion within an "incomplete series" rather than between series. The males' failure to ejaculate during these "incomplete series" was in part a function of female resistance. However, this did not appear to be the major factor involved. For example. there were many tests in which female resistance was either minimal or not apparent at all but the male was still unable to complete a series. In addition. "incomplete series" always contained far more intromissions than were required to produce ejaculation earlier in tests, far more even than in the last complete series. Thus, a change in the amount of stimulation required to produce ejaculation by the male appears to be an importani part of sexual satiety in this species.

Attainment of the satiety criterion within rather than between series contrasts sharply with every other rodent species studied to date except montane voles (Dewsbury. 1973). Theoretical implications of this type of satiety are treated in detail elsewhere (see Dewsbury, 1973). It might simply be mentioned here that sexual satiety in gerbils and montane voles cannot be accounted for by traditional models of rodent copulatory behavior (Beach, 1956: Beach \& Whalen. 1959: McGill, 1965). At least in these two species, sexual satiety appears to be a more complex process than formerly thought.

\section{REFERENCES}

Adler, N. T. Effects of the male's copulatory behavior on successful pregnancy of the female rat. Journal of Comparative \& Physiological Psychology, 1969, 69, 613-622.

Adler, N. T. \& Zoloth, S. R. Copulatory behavior can inhibit pregnancy in female rats. Science, $1970,168,1480-1482$.

Beach. F. A. Characteristics of masculine "sex drive." In M. R. Jones (Ed.), Nebraska stmposium on motivation. 1956. Lincoln: University of Nebraska Press, 1956. Pp. 1-36.

Beach. F. A., \& Jordan, L. Sexual exhaustion and recovery in the male rat. Quarterly Journal of Experimental Psychology, 1956, 7. 121-133.

Beach, F, A., \& Rabedeau, R. G. Sexual exhaustion and recovery in the male hamster. Journal of Comparative \& Phy siological Psychology. 1959.52.56-61.

Beach. F. A.. \& Whalen. R. E. Effects of ejaculation on sexual behavior in the male rat. Journal of Comparative \& Physiological Psychology, 1959, 52, 249-254.

Clemens, L. G. Mating behavior of the deermouse. Peromyscus maniculants gambeli. Doctoral dissertation. Lniversity of California. Berkeley. 1966.

Clenens. L. G. Experimental analysis of sexual behavior of the deermouse Peromy'scus maniculatus gambeli. Behaviour. 1969. $34,267.285$.

Dew sbury. D. A. Copulatory behavior of rats: Changes as satiety approaches. Psychological Reports, 1968, 22, 937-943.

Dewsbury, D. A. Copulatory behavior of rice rats (Oryzomys paulustris). Animal Behaviour, 1970, 18, 266-275.

Dewsbury. D. A. Copulatory behavior of old-field mice (Peromyscus polionotus subgriseus). Animal Behaviour, 1971. 19. 192-203

Dewsbury, D. A. Patterns of copulatory behavior in male mammals. Quarterly Review of Biology, 1972a, 47, 1-33.

Dewsbury. D. A. Copulatory behavior of cotton rats (Sigmodon hispidus). Zeitschrift für Tierpsychologie. $1972 \mathrm{~b} .30$ 477.487.

Dewsoury: D. A. Copulatory behavior of montane voles (Microtus montanis). Behaviour, 1973, 44, 186-202.

Gulotta, E. F. Meriones miguiculatus. Mammalian Species. 1971. 3. $1-5$.

Kuehn, R. E., \& Zucker, 1. Reproductive behavior of the Mongolian gerbil (Meriones unguiculatus). Journal of Comparative \& Physiological Psychology. 1968. 66. 747-752.

Larsson. $\mathrm{K}$. Conditioning and sexual beharior in the male albino rat. Stockholm: Almqvist \& Wiksell, 1956.

McGill, T. E. Studies of the sexual behavior of male laboratory mice: Effects of genotype. recovery of sex drive, and theory: In F. A. Beach (Ed.). Sex and behavior. New York: Wiley. 1965. Pp. 76-88.

Parkes, A. S., Mathews, L. H.. \& Rowlands, 1. W. Preface. In I. IV. Rowlands (Ed.). Comparative biologi of reproduction in mammals. New York: Academic Press, 1966.

Thiessen, D. D. The roots of territorial marking in the Nongolian gerbil: A problem of species common topography. Behavior Research Methods \& Instrumentation, 1968, 1. 70-76.

Wimer. B. J. Statistical principles in experimental design. New York: McGraw-Hill. 196?

(Receinad for publicition August 28.1973: revinint recived Ottober 1. 1973.1 